\title{
The Implementation of Reproductive Health Aspects of Global Strategy of Nutrition, Physical Activity and Health in Iran
}

\author{
MahsaMiryan $^{1}$ and Zahra Abbaspoor ${ }^{2 *}$ \\ ${ }^{1}$ Ahvaz Jundishapur University of Medical Sciences, Iran \\ ${ }^{2}$ Department of Midwifery, Ahvaz Jundishapur University of Medical Sciences, Iran
}

Submission: September 18, 2017; Published: October 18, 2017

*Corresponding author: Zahra Abbaspoor, Department of Midwifery, Ahvaz Jundishapur University of Medical Sciences, Ahvaz, Iran, Tel: 09166152841; Email: Abbaspoor_z762@yahoo.com

Abstract

Introduction: According to the World Health Organization report, the mortality and morbidity associated with non-communicable diseases is about $60 \%$ that it included about $47 \%$ of burden of diseases in the world. It is predicted that by 2020 this amount will increase to $73 \%$ and $60 \%$ respectively. Sixty percent of these deaths are happen in developing countries where the population is younger than developed countries. Due to the increase in these diseases in the world, the World Health Organization formulated and approved the global strategy of Nutrition, Physical Activity and Health. On the other hand, sexual and reproductive health problems provide $20 \%$ of the global burden ofdiseaseforwomenand $14 \%$ for men. In this paper, a comparative study of reproductive health aspects in this global strategy in Iran will be discussed.

Methods: This study is a comparative review with a web-based approach.

Results: in Iran the formulation of policies and appropriate goals and objectives in line with the nutritional global strategy has done, But regard to current situation in the country include the low average intake of vitamins A, B2, D, calcium and iron in rural and urban communities, the prevalence of stunting, moderate and severe under weight, zinc deficiency, suffering from severe anemia in adolescent girls and pregnant women, vitamin D and A deficiency in pregnant women will be increased, that due to the rapid nutrition transition in Iran the absence of attention to this important problems, they still remain unsolved or will progressed.

Conclusion: The results of this comparative study shows that nutritional policies in Iran is in line with the nutritional global strategy, However, operational planning and scheduling, particularly in the field of community education of healthy nutrition In order to achieve the objectives were not properly performed that need a serious attention of authorities in this field.

Keywords: Nutrition; Reproductive health; World health organization; Strategy

Abbreviations: WHO: World Health Organization; NCDs: Non-communicable Diseases

\section{Introduction}

Non communicable diseases, especially cardiovascular diseases, cancer, obesity and type 2 diabetes, are currently the most common causes of death in the world each year. These diseases impose a large burden on low- and middle-income countries with limited resources and still fighting against infectious diseases. Diet and exercise have recently been addressed by the World Health Organization and the Food and Drug Administration in the areas of diet, nutrition and disease prevention.

The History of Global Nutrition Strategy, Physical Activity and Health Turns out to the Global Health Strategy for All by 2000, which clearly highlights the importance of non-communicable diseases (NCDs) in developing and developed countries. In 1985, the thirty-fifth World Health Forum announced efforts to assess the significance of NCDs and their control programs, and finally, in 2004 [1] and at the Fifty-Seventh World Health Assembly, with the agreement of 192 member states and after 2 years of consultation with professional officials including members, other agencies in the United Nations, civil society and nongovernmental organizations and the private sector, this strategy was established [2-4].

This strategy pursues four main objectives, including: 
a. Reducing the risk of non - communicable disease risk factors.

b. Increasing the general knowledge and understanding of the impact of physical activity and nutrition on health.

c. Encouraging the development, strengthening and application of regional, national, Regional and global policies.

d. Assessment of scientific information and the main effects on diet and exercise [4].

On the other hand, the World Health Organization, based on the location of its six regions, has developed strategies and targets by 2019. This paper tries to compare global and regional strategies for nutrition, especially its operational objectives, with national nutrition strategies and goals in terms of reproductive health in Iran.

\section{Methods}

The present study is a comparative review study with a web-based approach. The main sources of data include: the 20year vision document, the 4th Economic, Social and Cultural Development Plan of the Islamic Republic of Iran, the National Document for the Trans boundary development of Food Security And Nutrition, developed by the Ministry of Health and Medical Education in 2004, the World Health Organization's Nutrition Report, 2004, the report of Regional Office for the Eastern Mediterranean of WHO in 2010, [5] Google Scholar and Medline.

\section{Results}

The World Health Organization's strategy and goals for reproductive health for eastern Mediterranean countries including Iran until 2019 include: Reducing the incidence of stunting and underweight among children, especially children under 5 years of age and nutritional deficiencies in women: (1Reducing the prevalence of underweight in children less than 5 years of age by $30 \% 2$. Reducing the prevalence of low birth weight of babies by $30 \% 3$. Increasing the percentage of exclusive breastfeeding in the first 6 months by $50 \% 4$-Increasing the percentage of trained mothers for supplemental nutrition in infants from 6 to 24 months (50\%). Reduced prevalence of micronutrient deficiencies: (1- Reduced prevalence of iron deficiency anemia in pre-school children, school age, reproductive aged and elderly women by 30\%, 2- Decreased prevalence of calcium and vitamin D deficiency in women of reproductive age, pregnant women and lactating mothers, 50\%. 3- Reduced prevalence of vitamin A deficiency in children under 5 years of age and pregnant and lactating mothers, 50\%.4.

Removal of iodine deficiency disorders by iodine salt intake by $50 \%$. 5 . Reducing the prevalence of NTD in neonates by $50 \%$. Reducing the prevalence of chronic diseases associated with nutrition:(1- Reducing the prevalence of overweight and obesity in children, adolescents, youth and adults by 35\%; 2- Increasing physical activity among children, adolescents, youth and adults by $75 \%$. 3 - Improve the dietary habits by $50 \%$. 4 . Reduce the incidence of diseases resulting from food by 50\%. (5In Iran, nutritional goals are in accordance with the policy and objectives of food security and nutrition in 2025 in four key areas of food security and nutrition include: 1- Reducing food insecurity in Iranian society to less than $10 \%$ in 2025 . 2. Reducing nutritional insecurity in Iranian society to less than $30 \%$ of the current situation in 2025; 3. Improvement of food safety and supply of safety food indexes by at least $30 \%$ in 2025. 4. Decrease of micronutrient deficiencies (iodine, iron, zinc, vitamin A, B and D), $70 \%$ of the current situation. 5- Promotion of culture and nutritional literacy up to $70 \%$ of the current situation [6].

Also, quantitative nutritional goals in the fourth development plan of the Iran economic and social development in the field of reproductive health include: reduction of malnutrition and micronutrient deficiencies, respectively, including: 1 . Decrease of $10 \%$ in the prevalence of malnutrition in children under 5 years of age in the height-to-age index. 2-A 10\%decrease in the prevalence of malnutrition in children less than 5 years of age, in a weight to age index. A decrease of $10 \%$ in the prevalence of $\mathrm{Zn}$ deficiency in different age groups. 4-A reduction of $10 \%$ in the incidence of severe iron deficiency. 5-A reduction of 10 $\%$ in the incidence of pregnant women in vitamin D deficiency 6-A reduction of $10 \%$ in women Pregnant women in vitamin A deficiency. 7-A 10\% decrease in people with overweight 8 Promoting the level of nutritional knowledge of different age groups, 25\% [7].

\section{Discussion}

Despite of the policy making and formulation of appropriate goals for the goals in line with the strategies of global nutrition, in case of unsatisfactory planning for the implementation of these approved policies, considering the current status of nutrition in Iran (the low average intakes of vitamins A and B2, calcium and iron In the urban and rural community, one in five children under 5 years of age have a stunt malnutrition, more than onesixth of children under 5 years of age with moderate and severe underweight, more than one third of children under the age of 2, adolescents and pregnant women with a Zinc deficiency, one third of children under the age of 2 years, adolescent girls and pregnant women have severe iron deficiency, at least onethird of pregnant women are vitamin $\mathrm{D}$ deficient with regard to the involvement of about one-fifth of pregnant women with vitamin A deficiency [7], Also, due to the fast pace of nutritional transition, in which malnutrition problems of energy protein and micronutrient deficiencies coincide with the problems associated with overeating, including obesity, diabetes, cardiovascular diseases in Iran, not a concise attention to this problem make this problem unresolved or even become greater.

\section{Conclusion}

Nutritional policies in Iran are in line with global nutrition policies and strategies, but the formulation and implementation 
of an operational, targeted and coherent plan for implementation of these policies is very important and necessary.

\section{References}

1. (2004) Bull World Health Organ 82(6) Geneva, Switzerland.

2. (2004) Global Strategy on Diet, Physical Activity and health.

3. (2003) WHO global strategy on diet, physical activity and health: SouthEast Asia regional consultation meeting report, New Delhi, India.
4. World Health Organization (2004) Global Strategy on Diet Physical Activity and Health. WHO, Geneva, Switzerland.

5. Regional Committee for the EM/RC57/4, (2010) Eastern Mediterranean September 2010, Fifty-seventh Session, Regional strategy on nutrition 2010-2019.

6. The Perspective of Iran 1404.

7. (2004) National Document for the Development of Food and Nutrition Security, the Fourth Economic, Social and Cultural Development Plan of the Islamic Republic of Iran.

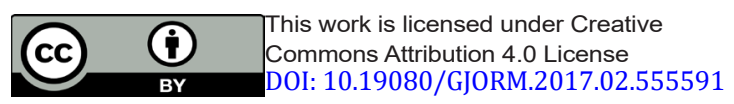

Your next submission with Juniper Publishers
will reach you the below assets
- Quality Editorial service
- Swift Peer Review
- Reprints availability
- E-prints Service
- Manuscript Podcast for convenient understanding
- Global attainment for your research
- Manuscript accessibility in different formats
( Pdf, E-pub, Full Text, Audio)
- Unceasing customer service
Track the below URL for one-step submission
https://juniperpublishers.com/online-submission.php

